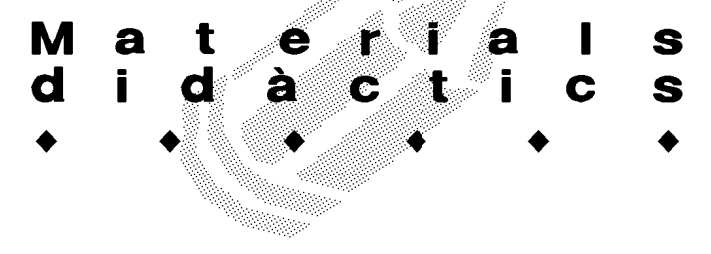

\title{
AL VOLTANT DE LA CATEDRAL
}

\author{
Josep Lluís Sebastià i Vidal. Inspector d'Ensenyament i coordinador del Camp \\ d'Aprenentatge de la ciutat de Tarragona
}

Val a dir que el text d'aquest article és el que s'utilitzà, bàsicament, en la presentació dels materials didàctics "Al voltant de la catedral", duta a terme el passat més de gener a l'antic refetó de la catedral de Tarragona.

Quan la Maria Joana Virgili, directora del Camp d'Aprenentatge de la ciutat de Tarragona i autora dels materials didàctics "Al voltant de la catedral", i alhora bona amiga, em va demanar que comentés el contingut didàctic i pedagògic dels materials didàctics que ha realitzat en el marc del Camp d'Aprenentatge de la ciutat de Tarragona, us he de dir que no em va costar gaire decidir-me a acceptar-ho.

La seva estima vers la catedral, acompanyada d'un profund coneixement fruit dels continuats treballs d'investigació realitzats, alguns publicats a Pallium, a Els vitralls del monestir de Santes Creus i la catedral de Tarragona, o en el volum XXI de la Catalunya Romànica entre d'altres, traspua en cadascun dels materials didàctics del conjunt que presentem. Val a dir que el treball pedagògic és complet i la metodologia aplicada la definiria com a vivencial i altament motivadora. Considera també totes les fases que corresponen a l'elaboració d'una proposta d'aquest tipus -avaluació inicial, interdisciplinària, inclosa en el currículum del nivell al qual s'adreça- a més que en demana la integració del professorat, en el decurs de l'experiència, com a element bàsic per a un resultat òptim.

\section{Característiques dels materials elaborats}

Dues són les idees fonamentals que es desenvolupen en el treball: estimular i aproximar els estudiants al coneixement científic i rigorós de la realitat de la catedral, sempre adaptat perfectament, al nivell al qual s'adreça cadascun dels treballs. És interessant el fet de com interrelaciona els diferents personatges vius, que comparteixen dia a dia, d'una manera o una altra, els espais catedralicis amb els muts testimonis, pacients i fidels, carregats de segles, que sostenen els nervis de les voltes o bé ornen els capitells, i que ens manifesten el desencís de la seva solitud, amb la prima esperança d'arrencar un somriure a un infant. I aquí sí que podem parlar que són els alumnes, per mitjà de les propostes didàctiques, els que investiguen, descobreixen i construeixen la historia de la seu.
Com a conclusió a aquesta primera generalització, en destaco la idea bàsica entorn de la qual ha desenvolupat el treball: Coneixer el passat per actuar convenientment en el present, a fi de millorar en el futur els nostres monuments, i la interpretació vàlida, vinculantla al nostre context històric i destacant-ne els elements diferenciadors i característics de la nostra catedral.

Pel que fa a l'aspecte de difondre'n el seu coneixement $\mathrm{i}$ en lògica conseqüència la seva estima, passo a comentar-vos els tres treballs elaborats i experimentats, centrats a mostrar la nostra catedral des de diferents franges d'edat: El zoo petri (5-7 anys), Descobreix els secrets de la catedral (8-12 anys) i el Museu diocesà (12-18 anys); cadascun d'ells comprèn una guia didàctica, dirigida als professors, un quadern de treball per a l'alumne i materials auxiliars manipulatius exposats en la sala, a més d'un CD realitzat per Josep Serra.

\section{El zoo petri (5-7 anys)}

Els animals són personatges entranyables en la vida dels infants. Són presents en els seus jocs, protagonistes dels seus somnis i éssers molt propers al seu món quotidià. Doncs bé, portem-los a la catedral i descobrirem bèsties i animals de fa uns 800 anys: ocells, serps de cues llargues i cargolades, àligues, dracs, conills, galls i altres bèsties que ens esperen. Però són reals o fantàstics? Se'n veuen d'aquest estil pel carrer? Per descobrir- ho, l'autora apropa l'alumne, des d'una òptica creativa i sensible, a la catedral, a l'entorn de diferents vessants: la plàstica, l'expressió oral i escrita, la música i les ciències naturals i socials. És, per tant, una activitat interdisciplinària dirigida a cicle inicial o al tercer curs de Parvulari, segons el grau de desenvolupament dels infants.

L'objectiu fonamental perseguit és potenciar un contacte directe i pràctic amb la seu, emprant les tècniques d'observació i l'ajut d'un divertit i estrany passeig per les representacions zoomòrfiques dels capitells, retaules, mènsules, àbacs... que esdevingui el factor motivador $\mathrm{i}$ provocador dels descobriments.

M. Joana considera el joc com a procediment més adequat per actuar com a fil conductor de l'activitat, ja que és una situació natural de l'acció infantil, on es troben unes possibilitats extraordinàries de desenvolu- 


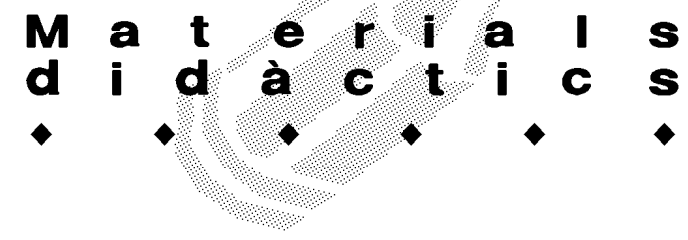

pament afectiu, social i intel-lectual. Així doncs, fent servir el joc com a base, s'inicia els infants en el concepte de la història. En definitiva, intenta una aproximació al món de l'escultura medieval.

El conjunt de les activitats responen a tres fases. En la primera, es vol familiaritzar l'alumne amb els animals i posar-lo en contacte amb diferents formes de representar-los. La segona se centra en dues parts estretament vinculades: una visita a la catedral i un taller. Finalment, el nen haurà d'explicar els coneixements adquirits i ampliar-los mitjançant poemes, cançons, endevinalles, contes, dites i frases fetes, trencaclosques i embarbussaments.

El lent passeig pels diferents indrets de la catedral permet aturar-se davant de les obres zoomòrfiques prèviament seleccionades. En fan una lectura dels aspectes visuals, provoquen un diàleg de cadascun dels animals observats i els motiven perquè expliquin el que hi veuen i el que pensen. Observen alhora les característiques morfològiques (llana, potes, ales, plomes...), funcionals (què mengen, on viuen, quins sons emeten...) i n'apunten una classificació (ocells, mamífers, monstres o éssers reals, salvatges...). D'altra banda, intenten descobrir el missatge subjectiu que transmet als infants cadascuna de les imatges (admiració, rebuig, por...), sempre lligada al context on es troba, i finalment fa l'estudi del gest.

La importància del món imaginari, que els contes tenen per als nens en aquest període infantil, on es canalitzen molts dels sentiments, emocions, pensaments, dubtes, angoixes i pors, propis de persones que encara no tenen prou clars els límits entre la realitat i la fantasia, l'aprofita per explicar les faules d'Esop: La processó de les rates i El llop i la cabra. Les seqüències de les imatges de la primera, esculpides en un àbac del claustre, permeten desenvolupar, a bastament, la fantasia infantil i admirar l'escena cisellatda en marbre. Aquest camí, l'infant el fa de la mà del mestre, enmig d'un clima d'expectació, distès, capaç d'embolcallar-lo en l'emoció, i amb el temps, el conduirà a la valoració, estima i respecte vers les obres d'art.

Proposa, com a segona part de la visita, la realització d'un taller d'expressió plàstica perquè entén que expressar un coneixement més enllà dels límits de l'aprenentatge concret significa que l'infant l'ha interioritzat. Treballa la imaginació, i a partir d'un ou, trobat en un indret secret de la catedral, els demanarà la creació d'un animal (real o fantàstic, bo o dolent...), primer en dibuix i després en fang. El pas de la imatge bidimensional a la tridimensional estimula el seu enginy i creativitat i es tradueix en respostes plàstiques expressives. De l'animal, s'haurà d'imaginar la forma, el color, la pell, el pèl o les plomes, la mida, què menja, com es belluga, quant de temps viu, on viu... en definitiva, n'ha d'inventar la seva història.

Una vegada construït, s'asseuran entorn d'un cercle dividit en quatre parts, en el qual diferents colors simbolitzen els elements (aire, aigua, foc i terra), i presentaran i col-locaran el seu animal, segons el medi on hagin decidit que viurà. En aquesta fase és important l'expressió artística i verbal de tot allò que al llarg de l'activitat han observat, imaginat $\mathrm{i}$ els ha impressionat. En el decurs de la presentació s'establirà un diàleg en el qual intervindrà més d'un interlocutor. Se'ls demanarà que facin la seva presentació amb claredat i que respectin el torn de paraula.

Ha procurat també que els poemes i les cançons seleccionades, com El drac màgic i El lleó, donin elements suficients perquè es puguin relacionar amb característiques o fets rellevants dels diferents animals petris de la catedral, i fins i tot s'ha reproduït el drac en fang, a fi d'aconseguir el seu apropament a l'infant.

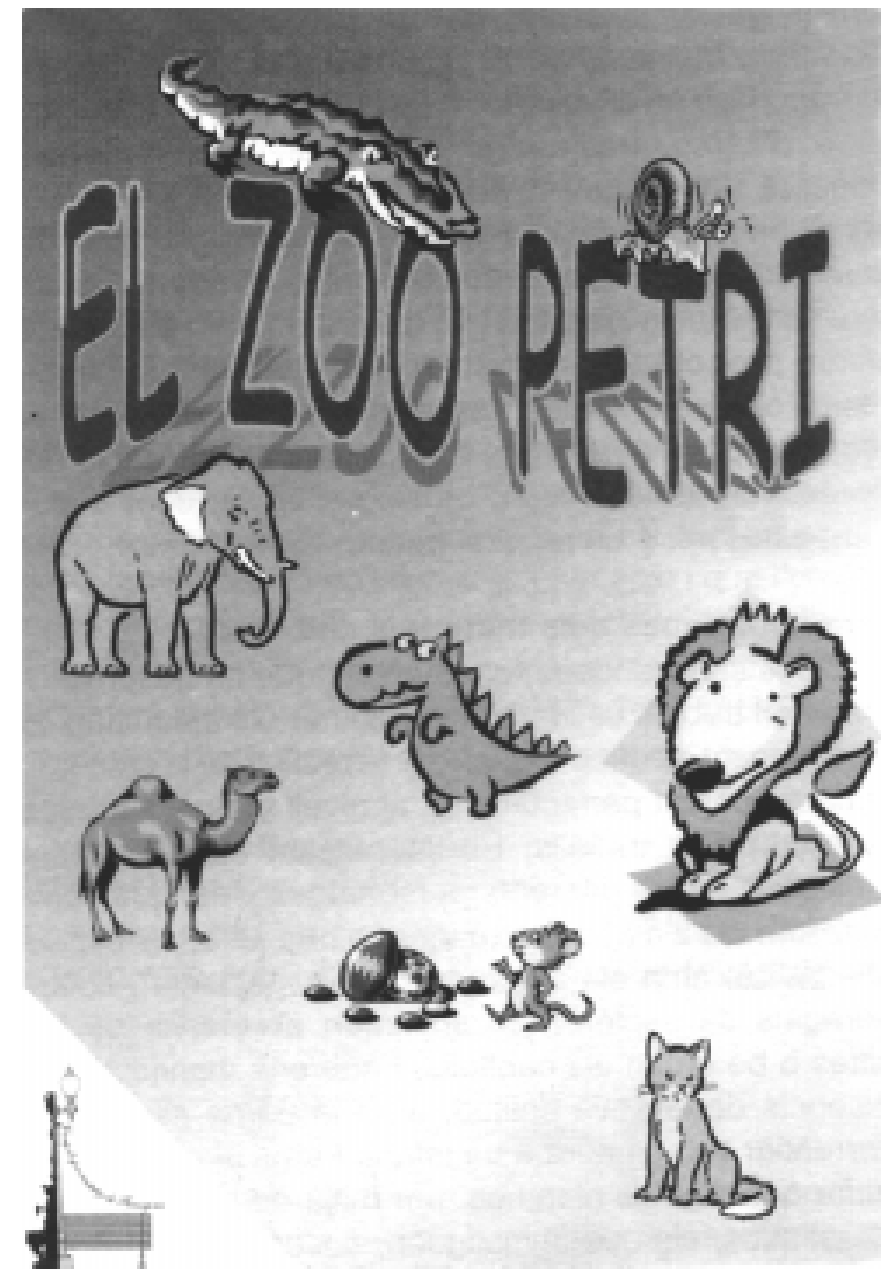




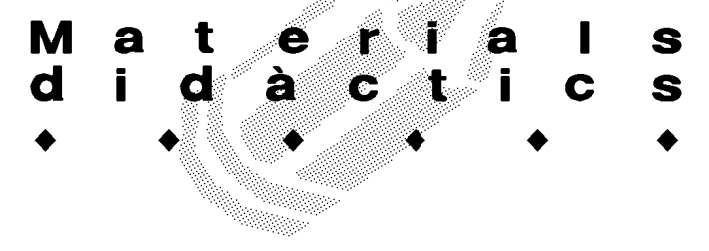

\section{Descobreix els secrets de la catedral (8-12 anys)}

Aquesta és una activitat que ens convida a mirar-la amb ulls d'infant, i sobretot a viure-la, a descobrir-la tot ignorant el romànic $i$ el gòtic. En definitiva, ens convida a gaudir d'un matí plaent, jo diria que en majúscules, a la nostra seu. Ens proposa, doncs, una primera aproximació dels alumnes de cicle mitjà o superior, a la catedral.

Es tracta d'una activitat lúdica i engrescadora, basada en la descoberta i el joc, com a elements substancials per a la comprensió i el seu coneixement. Realitzada a partir dels interessos propis dels infants d'aquesta edat, pretén aconseguir que aprenguin mentre juguen, vegin alhora que mirin i s'adonin que l'art i el nostre entorn no són quelcom estrany, sinó que poden veure, tocar, inspeccionar i descobrir, a través seu, un món fins ara desconegut. Vol aconseguir un nen-descobridor que tingui la sensació, real per a ell, que va coneixent noves coses a partir de la descoberta. Així, intenta jugar amb la investigació i posar de relleu una bona dosi d'aventura, partint de la seva curiositat personal, pròpia d'aquesta edat, a cavall entre la realitat i la ficció, i penso que s'aconsegueix plenament, amb una experiència excitant i divertida que permetrà futurs aprenentatges significatius.

Com a factor motivador previ a la sortida recomana, molt encertadament, la lectura del llibre de Jordi Tortosa El fantasma de la catedral, el qual amb l'excusa de la intriga i del misteri fa un recorregut per diferents espais de la seu, que els alumnes podran visionar a posteriori.

En el decurs de l'activitat ens adonarem que alguns dels conceptes contemplats en Ciències Socials i que ens semblava que quedaven molt llunyans de les capacitats dels nostres alumnes, com l'epigrafia, la iconografia, les sensacions... són perfectament assimilables en aquests nivells. Passejant per les galeries claustrals localitzaran les petites mènsules "fent ganyotes"; jugaran al joc del follet; llegiran, interpretaran i comprovaran fonts històriques, tot descobrint el gegant de 12 pams d'alçària soterrat en el claustre; gaudiran escoltant la faula d'Esop cisellada en un dels àbacs. Finalment entraran en el temple i embadocats amb ulls d'infants percebran les sensacions, és a dir, allò que hi és però no és veu: l'olor d'encens, el recolliment, l'ombra confosa amb les suaus notes de l'orgue i el toc de la vedada a l'hora de l'àngelus. Descobriran la fauna autòctona en les escenes de la predel.la com: l'aranya, les mosques, el cargol, el llangardaix, la granota... Des de dalt del campanar contemplaran l'esplèndida vista que ens ofereix la ciutat, a més de veure in situles campanes de la nostra seu. I a la fi, cansats, reposaran en el cadirat del presbiteri, i la cadira sobretitulada "CHORUS" s'afegirà a la màgica visita, trontollant per la força d'un vent

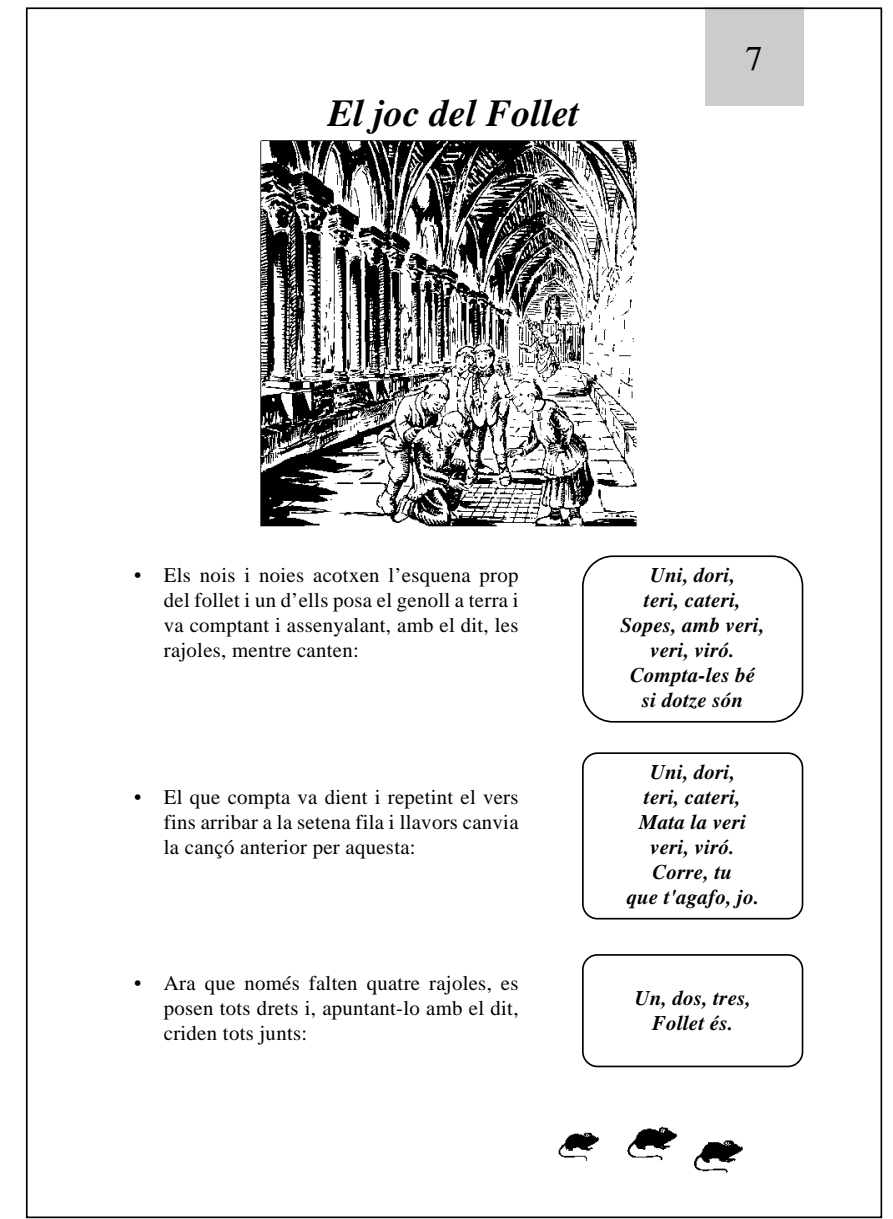

inexistent i a la fi el sagristà descobrirà l'entrada secreta a una dependència de la seu. Abans de marxar queden dues coses per veure: l'escala on el lladre va amagar el preuat tresor catedralici i la comprovació, tot encerclant un dels pilars, de la impressionant arquitectura del temple.

\section{Museu diocesà (12-18 anys)}

La proposta didàctica centrada en el Museu diocesà de Tarragona va dirigida preferentment a alumnes d'ESO i Batxillerat i té com a objectiu descobrir uns mecanismes d'aproximació a l'obra d'art, que seran desenvolupats en nivells superiors, i que no són res més que les capacitats innates de reflexió i observació. L'estudi de les peces des de l'àmbit històric, cultural i artístic, a més de l'espai físic que ocupaven originàriament i la seva utilitat, ha permès resoldre satisfactòriament la dificultat d'interpretació i comprensió que presenten en l'exposició les obres religioses, col-locades unes al costat de les altres i amb funcions i situacions diverses.

Els treballs previs són destinats a aprendre a llegir 


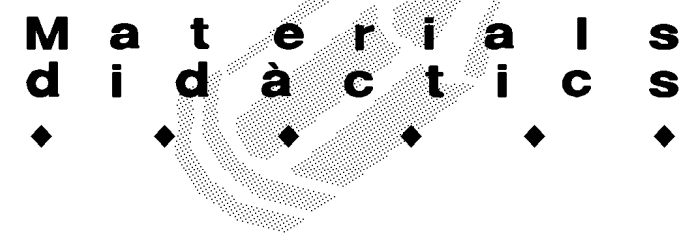

una obra d'art. Però per fer-ho han de conèixer la seva llengua, les seves paraules i les seves combinacions, després esbrinar-ne el sentit, i en darrer terme, establir la seva causa, la seva finalitat. Els exercicis preparats per superar aquestes dificultats faciliten el coneixement d'un vocabulari específic a més de contextualitzar les peces de roba litúrgica, ornaments emprats per un arquebisbe com el bàcul, la mitra, el pal.li..., saber anomenar i ubicar les diferents parts d'un retaule, etc. Contemplen també les de funcionalitat i ubicació dels estris emprats en la litúrgia actual o antiga com crismeres, encencers, custòdies, calzes... o bé de coneixement de tècniques utilitzades com els colors estudiats segons l'escala de gradació (freds i calents), el seu valor (contrast i ombres), les accions escenificades (pacífiques o violentes) i les sensacions (alegria o dolor). Atorga una importància considerable al coneixement dels oficis que intervenen en l'elaboració d'una obra d'art, destacantne sobretot els que es troben en perill de desaparició com el de vitrallers en la fabricació del vidre de ciba o de manxó, el coneixement de la necessitat de les marques de col-locació o la decoració d'un plafó, a més de personatges que intervenen en l'elaboració de còdexs miniats com l'enquadernador, l'escrivà, el pergaminador, el miniaturista o l'il.luminador.

Si hi sabem llegir, les peces que se serven en el museu ens expliquen la història de la catedral, la del seu entorn i la dels seus homes. Així, les 280 obres enregistrades vénen a ser com una mena d'espinetes que estan a l'aguait de tot el que hi passa, i esperen, potser, retornar al seu lloc d'origen, però mentrestant, cal despertar-les, donar-los "vida", jugar-hi, i convertir la contemplació dels objectes de la vida dels nostres avantpassats en una activitat divertida i plena de descobriments. Com fer-ho? Com es poden convertir les obres estàtiques en dinàmiques? Com podem aconseguir escoltar-les? Calia cercar procediments atractius i diferents tot aplicant una gran dosi d'imaginació, i ho ha fet. Així, tot prioritzant el treball en grup per sobre de les activitats individuals, podem visualitzar fonts històriques, completar dibuixos, recuperar blasons, descobrir la promesa de l'amor etern entre esposos i el nom de les seves robes, observar com els Nens s'han escapat de la Mare... i jocs manipulatius amb trencaclosques vítrics rèpliques d'imatges que escenifiquen les reals, un tornicub que ens apropa el bonic enteixinat de la sagristia i fins i tot un tapís on els personatges s'han dividit per famílies. Els treballs proposats condueixen l'alumne a realitzar-los amb rigor i coneixement científic, i s'insereixen de forma seriosa en els valors, actituds i normes. Però per damunt de tot ensenyen a aprendre a mirar i a descobrir la bellesa de la peça en si mateixa.

L'enhorabona a l'autora, al realitzador del $C D$, als fotògrafs, als dibuixants $i$ a tots aquells que han fet possible l'edició d'aquest magnífic treball que avui ens ofereix el Camp d'Aprenentatge de la ciutat de Tarragona, gràcies al qual i a tot el seu professorat (M. Antònia Ibáñez, Rosa Moragues, Jordi Tortosa i M. Joana Virgili) ens faran viure la gran descoberta de la seu tarragonina. Potser nosaltres mateixos i els nostres infants podrem conèixer millor un dels tresors més preuats del patrimoni artístic de la Catalunya Nova.
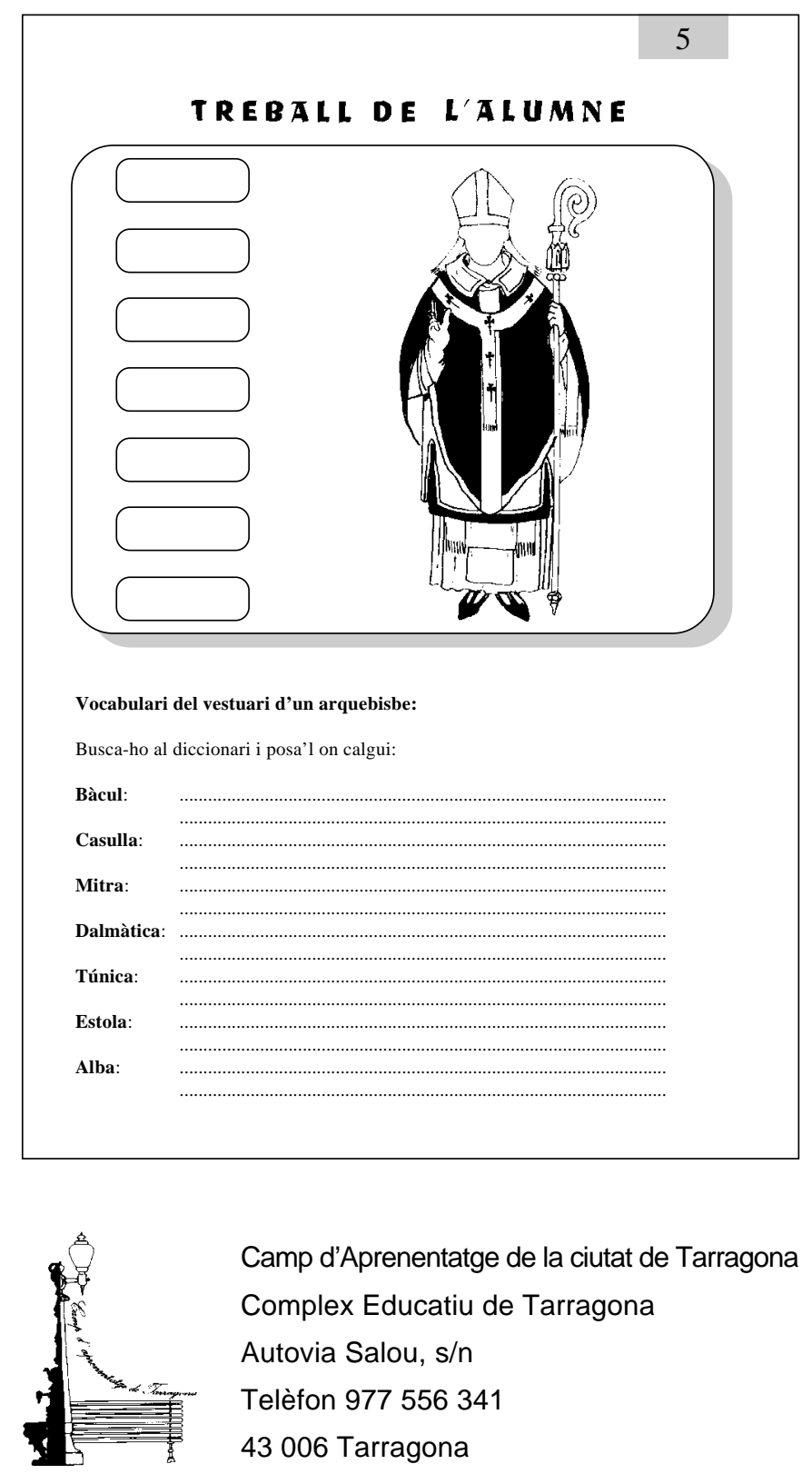

Camp d'Aprenentatge de la ciutat de Tarragona Complex Educatiu de Tarragona

Autovia Salou, s/n

Telèfon 977556341

43006 Tarragona 